\title{
Importance of maintaining good oral health in cardiometabolic disorders
}

\section{Pussinen, Pirkko J.}

2018-11-15

Pussinen , P J , Malle , E \& Sattler , W 2018 , ' Importance of maintaining good oral health in cardiometabolic disorders ' , International Journal of Cardiology , vol. 271 , pp. 291-292 . https://doi.org/10.1016/j.ijca

http://hdl.handle.net/10138/306605

https://doi.org/10.1016/j.ijcard.2018.07.014

publishedVersion

Downloaded from Helda, University of Helsinki institutional repository.

This is an electronic reprint of the original article.

This reprint may differ from the original in pagination and typographic detail.

Please cite the original version. 


\title{
Importance of maintaining good oral health in cardiometabolic disorders
}

\author{
Pirkko J. Pussinen ${ }^{\mathrm{a}, *, 1}$, Ernst Malle ${ }^{\mathrm{b}, 1}$, Wolfgang Sattler ${ }^{\mathrm{b}, 1}$ \\ a Department of Oral and Maxillofacial Diseases, University of Helsinki, Helsinki University Hospital, Helsinki, Finland \\ b Molecular Biology and Biochemistry, Gottfried Schatz Research Center, Medical University of Graz, Graz, Austria
}

\section{A R T I C L E I N F O}

\section{Article history:}

Received 26 June 2018

Accepted 2 July 2018

Available online 4 July 2018

\section{Keywords:}

Inflammation

Infection

Myeloperoxidase

Oral infections

Endotoxemia

Lipopolysaccharide

The association between periodontitis (Fig. 1), one of the most common bacterial-induced chronic inflammatory diseases in adults, and increased risk for atherosclerotic cardiovascular disease (CVD) is established, although the evidence that the treatment of periodontitis would reduce major adverse events is scarce and mainly circumstantial. Interestingly, Sen and co-workers [1] published recently that regular dental care was associated with decreased risk for incident stroke compared to no dental care or episodic care only when symptoms arise.

In the present issue of International Journal of Cardiology, Masi and co-workers [2] investigated the effect of periodontal treatment on the formation of mitochondrial reactive oxygen species (mtROS) in a carefully performed randomized controlled trial of patients with type 2 diabetes. All patients were assigned to treatment due to moderate to severe periodontitis, and they were randomized to receive either control or intensive periodontal treatment (IPT). After six months, the patients in the IPT group presented improvement in interferon- $\gamma$ (IFN- $\gamma$ ), tumour necrosis factor- $\alpha$, and soluble adhesion molecule concentrations, as well as measures of lipopolysaccharide (LPS) activity, endothelial function, and metabolic control. Importantly, the IPT group presented with a lower production of mtROS due to reduced oxidative

\footnotetext{
DOI of original article: https://doi.org/10.1016/j.ijcard.2018.05.019.

* Corresponding author at: Oral and Maxillofacial Diseases, University of Helsinki, P.O. Box 63, FI-00014 Helsinki, Finland.

E-mail address: pirkko.pussinen@helsinki.fi (P.J. Pussinen).

1 These authors take responsibility for all aspects of the reliability and freedom from bias of the data presented and their discussed interpretation.
}

stress in lymphocytes. Among the parameters measured, the lymphocyte mtROS level was the only predictor of endothelial (dys) function.

According to the present hypothesis, low-grade systemic inflammation is the etiopathogenic link between periodontitis and CVD. In addition to locally produced inflammatory mediators, the oral bacterial challenge contributes to systemic inflammation. The ultimate goal of periodontal treatment is to remove the dysbiotic biofilm in order to restore the host-microbial homeostasis. This treatment needs to be aggressive enough to produce beneficial results both locally and systemically as reported by Masi and co-workers [2]. One of the major bacterialderived mediators of systemic effects is LPS, an important virulence factor of gram-negative bacteria, which have a dominance in the periodontitis-associated microbiota. The translocation of LPS into the circulation may occur directly or through inflamed and bleeding periodontal tissues, lymph vessels, or saliva [3], resulting in endotoxemia. Endotoxemia is recognized as an independent risk factor for both incident coronary artery disease and diabetes [4]. In the study by Masi and co-workers [2], serum LPS activity, i.e. endotoxemia, ended up on a lower level in the IPT than in the control group after the treatment period.

As a Toll like receptor-ligand, LPS is able to induce mtROS formation in immune cells. mtROS are involved in pathogen-host interactions including several pathways crucial for immune responses, such as apoptosis, autophagy, inflammation, and bactericidal effects [5]. Masi and co-workers [2] detected most pronounced effects of IPT on mtROS reduction in the lymphocyte fraction. In lymphocytes, as in other immune cells, superoxide anion radical $\left(\mathrm{O}_{2}^{-\circ}\right)$ can be produced by $\mathrm{NADPH}$ oxidase(s) or as a result of electron leakage in mitochondria. Although mtROS were initially considered as toxic by-products of oxidative metabolism, they are continuously generated and, at physiological levels, regulate essential cellular processes [6].

Among other sources, complex I and III of the mitochondrial electron transport chain represent major sites of $\mathrm{O}_{2}^{-\circ}$ formation. $\mathrm{O}_{2}^{-\circ}$ is a shortlived radical and it dismutates to $\mathrm{H}_{2} \mathrm{O}_{2}$ and $\mathrm{O}_{2}$ in a reaction occurring either spontaneously or in a superoxide dismutase-catalysed manner. In contrast to $\mathrm{O}_{2}^{-\circ}, \mathrm{H}_{2} \mathrm{O}_{2}$ is electrically neutral, diffuses across cellular membranes, and acts as second messenger during lymphocyte activation [7]. Of note, mtROS production by an intact complex III is required for T-cell activation and IFN- $\gamma$ secretion from stimulated leukocytes. Thus, decreased LPS and mtROS formation could lead to attenuated IFN- $\gamma$ secretion as reported [2].

Whether or not the ROS-toxifier myeloperoxidase, which converts the relatively non-toxic $\mathrm{H}_{2} \mathrm{O}_{2}$ to the potent oxidant hypochlorous acid 


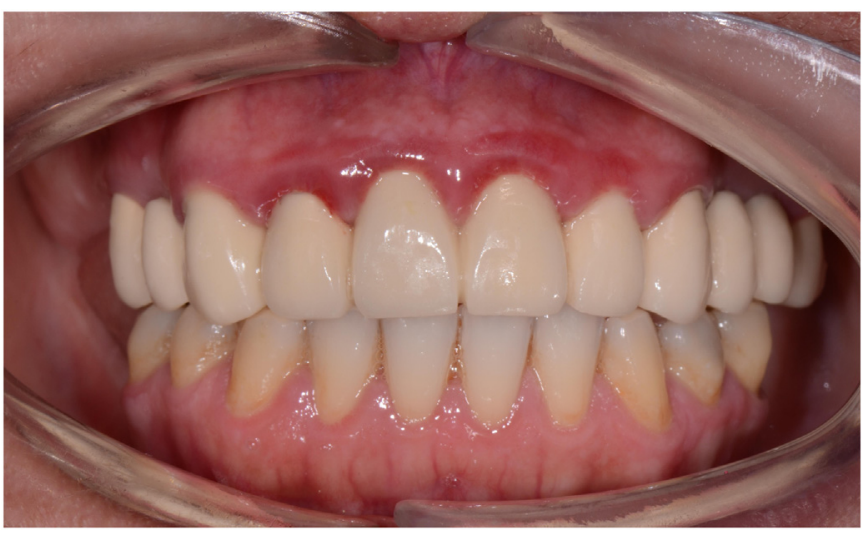

Fig. 1. Clinical picture of periodontal disease. A gingivitis patient has bleeding gums with classical signs of inflammation: pain, redness, and swelling. Plaque-induced gingivitis is a reversible state without destruction of connective tissue. Gingivitis may transform into periodontitis in susceptible individuals and always precedes periodontitis, which is characterized by an irreversible loss of tooth-supporting tissues. Periodontal diseases are always diagnosed by a dentist and require professional treatment.

[8], is reduced in patients undergoing ICT was not addressed in the study by Masi and co-workers [2]. This could be of importance since the neutrophil proteolytic activation cascade represents an apparent mechanistic link between periodontitis and coronary heart disease and high levels of myeloperoxidase, a heme protein abundantly present in neutrophils, are associated with periodontitis, diabetes, CVD, and endothelial dysfunction $[8,9]$.

The systemically beneficial effects of periodontal treatment most likely involve decreased endotoxemia leading to reduction of the inflammatory responses. This affects several pathways involved in atherogenesis, such as lipoprotein composition and function, glucose metabolism, complement cascade, contact activation, leukocyte migration, vascular permeability, and oxidative stress. Indeed, proper periodontal treatment can improve cardiovascular risk factors: according to a recent meta-analysis plasma concentrations of inflammatory, thrombotic, and metabolic markers decrease and endothelial function improves [10]. The association between poor oral and general health has been under intense research for decades. However, counselling patients on the importance of maintaining good oral health and visiting dental professionals regularly is only rarely given by cardiologists, neurologists, or general medical practitioners. Even though chronic oral infections would not be causally linked with cardiometabolic disorders, it is time to merge oral health care with the health care of the rest of the body.

\section{Conflict of interest}

The authors report no relationship that could be constructed as a conflict of interest.

\section{Acknowledgements}

The clinical picture is a kind gift from Dr. Kåre Buhlin and Dr. Jacob Holmer from Karolinska Institutet, Sweden.

\section{References}

[1] S. Sen, L.D. Giamberardino, K. Moss, T. Morelli, W.D. Rosamond, R.F. Gottesman, J Beck, S. Offenbacher, Periodontal disease, regular dental care use, and incident ischemic stroke, Stroke 49 (2018) 355-362, https://doi.org/10.1161/STROKEAHA. 117.018990 .

[2] S. Masi, M. Orlandi, M. Parkar, D. Bhowruth, I. Kingston, C. O'Rourke, A. Virdis, A Hingorani, S.J. Hurel, N. Donos, F. D'Aiuto, J. Deanfield, Mitochondrial oxidative stress, endothelial function and metabolic control in patients with type II diabetes and periodontitis: a randomised controlled clinical trial, Int. J. Cardiol. (2018 Aug 1) https://doi.org/10.1016/j.ijcard.2018.05.019.

[3] J.M. Liljestrand, S. Paju, K. Buhlin, G.R. Persson, S. Sarna, M.S. Nieminen, J. Sinisalo, P. Mäntylä, P.J. Pussinen, Lipopolysaccharide, a possible molecular mediator between periodontitis and coronary artery disease, J. Clin. Periodontol. 44 (2017) 784-792, https://doi.org/10.1111/jcpe.12751.

[4] K.A. Kallio, K.A. Hätönen, M. Lehto, V. Salomaa, S. Männistö, P.J. Pussinen, Endotoxemia, nutrition, and cardiometabolic disorders, Acta Diabetol. 52 (2015) 395-404, https://doi.org/10.1007/s00592-014-0662-3.

[5] J. Dan Dunn, L.A. Alvarez, X. Zhang, T. Soldati, Reactive oxygen species and mitochondria: a nexus of cellular homeostasis, Redox Biol. 6 (2015) 472-485, https://doi.org/10.1016/j.redox.2015.09.005.

[6] S.E. Weinberg, L.A. Sena, N.S. Chandel, Mitochondria in the regulation of innate and adaptive immunity, Immunity 42 (2015) 406-417, https://doi.org/10.1016/j. immuni.2015.02.002.

[7] L.A. Sena, S. Li, A. Jairaman, M. Prakriya, T. Ezponda, D.A. Hildeman, C.R. Wang, P.T. Schumacker, J.D. Licht, H. Perlman, P.J. Bryce, N.S. Chandel, Mitochondria are required for antigen-specific T cell activation through reactive oxygen species signalling, Immunity 38 (2013) 225-236, https://doi.org/10.1016/j.immuni.2012.10.020.

[8] M. Davies, C.L. Hawkins, D.I. Pattison, M.D. Rees, Mammalian heme peroxidases: from molecular mechanisms to health implications, Antioxid. Redox Signal. 10 (2008) 1199-1234, https://doi.org/10.1089/ars.2007.1927.

[9] H. Alfakry, E. Malle, C.N. Koyani, P.J. Pussinen, T. Sorsa, Neutrophil proteolytic activation cascades: a possible mechanistic link between chronic periodontitis and coronary heart disease, Innate Immun. 22 (2016) 85-99, https://doi.org/10.1177/ 1753425915617521.

[10] W.J. Teeuw, D.E. Slot, H. Susanto, V.E. Gerdes, F. Abbas, F. D'Aiuto, J.J. Kastelein, B.C. Loos, Treatment of periodontitis improves the atherosclerotic profile: a systematic review and meta-analysis, J. Clin. Periodontol. 41 (2014) 70-79, https://doi.org/10. 1111/jcpe.12171. 